\title{
A DISTRIBUIÇÃO DINÂMICA DO ÔNUS PREVISTA NO CÓDIGO DE PROCESSO CIVIL DE 2015 E SUA INCIDÊNCIA NO PROCESSO DO TRABALHO
}

\section{THE DYNAMIC DISTRIBUTION OF THE GUIDANCE PROVIDED FOR IN THE 2015 CIVIL PROCESS CODE AND ITS INCIDENCE IN THE LABOR PROCESS}

Priscila Martins Reis Machado ${ }^{1}$

\section{RESUMO}

O tema central deste estudo consiste na análise dos reflexos do art. $373, \S^{\circ}{ }^{\circ}$ do CPC/2015, que prevê a aplicabilidade da distribuição dinâmica do ônus da prova no processo civil brasileiro, na seara laboral. No que diz respeito ao ônus da prova, o CPC/1973 adotava referencial estático (art. 333), entregando ao autor o ônus de provar os fatos constitutivos de seu direito e ao réu provar fatos extintivos, modificativos e impeditivos do direito; enquanto a CLT limitava-se a sustentar que a prova das alegações incumbe à parte que as fizer, cuidando a jurisprudência de estabelecer algumas adaptações nessa seara. A teoria da distribuição dinâmica do ônus da prova, gestada na Argentina no final do século XX e recebida expressamente pelo $\mathrm{CPC} / 2015$, ao admitir a possibilidade de o juiz modificar de forma fundamentada o ônus da prova quando essa medida revelar-se adequada e necessária, caminha no sentido de garantir efetividade à atuação jurisdicional. Dada a relevância da temática, este estudo pretende aprofundar acerca da aplicabilidade da carga dinâmica prevista no CPC/2015 na seara trabalhista. Para atingir esse escopo, será empreendida uma análise da evolução normativa atinente à carga probatória, examinando-se a legislação pátria e a doutrina brasileira e estrangeira. Será atribuído enfoque especial à doutrina Argentina pelo fato de ser responsável pelas primeiras manifestações acerca da carga dinâmica da prova. Após, serão avaliados possíveis contextos a exigir a flexibilidade do ônus em relações processuais trabalhistas.

Palavras-chave: Ônus da prova. Carga dinâmica. Garantias processuais. Efetividade.

\footnotetext{
${ }^{1}$ Doutoranda em Direito pela Pontifícia Universidade Católica de Minas Gerais (PUC Minas). Mestre em Direito pela Universidade Federal de Minas Gerais. Bacharel em Direito pela Universidade Federal de Minas Gerais. Advogada. Professora Assistente do Instituto Belo Horizonte de Ensino Superior (IBHES) e da Faculdade de Ensino Minas Gerais (FACEMG). E-mail: mreispriscila@hotmail.com
} 


\section{ABSTRACT}

The central theme of this study is the analysis of the reflexes of art. $373, \S 1$ of CPC / 2015 , which provides for the applicability of the dynamic distribution of the burden of proof in Brazilian civil proceedings, in the labor court. Regarding the burden of proof, CPC / 1973 adopted a static reference (article 333), giving the author the burden of proving the facts that constituted his right and the defendant to prove extinguishing facts, modifying and impeding the law; while the CLT merely argued that it was for the party making them to prove the allegations, taking into account the case-law of making certain adjustments in that area. The theory of the dynamic distribution of the burden of proof, developed in Argentina in the late twentieth century and expressly received by the CPC / 2015, admitting the possibility of the judge to modify in a justified manner the burden of proof when this measure proves adequate and necessary, walks in the sense of guaranteeing effectiveness to the jurisdictional action. Given the relevance of this issue, this study intends to examine the applicability of the dynamic load foreseen in the CPC / 2015 in the labor sector. In order to reach this scope, an analysis of the normative evolution regarding the burden of proof will be undertaken, examining the Brazilian legislation and the Brazilian and foreign doctrine. Special emphasis will be placed on the doctrine of Argentina because it is responsible for the first manifestations about the dynamic load of the test. Afterwards, possible contexts will be evaluated, demanding the flexibility of the burden of labor procedural relations.

Keywords: Burden of proof; Dynamic load; Procedural safeguards; Effectiveness.

\section{INTRODUÇÃO}

A edição do Código de Processo Civil de 2015 (CPC/2015) trouxe consigo importantes inovações no campo do Processo do Trabalho. Dentre tais medidas encontra-se o disposto no art. 373, $\S 1^{\circ}$ do CPC/2015 acerca da recepção expressa da dimensão dinâmica do ônus da prova ao permitir ao julgador modificar o esquema estático do ônus probatório em determinadas situações justificadas.

No que diz respeito ao ônus da prova, o Código de Processo Civil de 1973 (CPC/1973) adotava referencial estático (art. 333), entregando ao autor o ônus de provar os fatos constitutivos de seu direito e ao réu o de produzir provas acerca de fatos extintivos, modificativos e impeditivos do direito. 
De outro lado, na esfera laboral, a CLT limitava-se a sustentar que a prova das alegações incumbe à parte que as fizer, cuidando a jurisprudência de estabelecer algumas adaptações nessa seara a exemplo do contido nas súmulas 338 e 461 do Tribunal Superior do Trabalho.

A teoria da distribuição dinâmica do ônus da prova gestada na Argentina no final do século XX e recebida expressamente pelo CPC/2015 confere à instrução processual uma natureza dinâmica e flexível, permitindo reajustes a depender dos reclames do caso em apreciação judicial.

Vale ressaltar que o instituto não se confunde com a inversão do ônus da prova, não tendo como efeito a inversão completa do ônus probatório da matéria em juízo. Sua aplicação deve ser realizada de maneira específica e fundamentada, evitando discrepâncias processuais e violação ao contraditório e à ampla defesa.

Considerando a relevância da temática e sua aptidão para aprimorar as ferramentas processuais disponíveis no sentido de tornar o processo mais efetivo, garantindo os direitos fundamentais das partes, este estudo pretende aprofundar acerca da aplicabilidade da carga dinâmica prevista no CPC/2015 na seara trabalhista.

Para atingir esse escopo, será empreendida uma breve análise acerca dos caracteres principais da prova e do ônus probatório, examinando-se as teorias propostas para a sua distribuição entre as partes litigantes. Nesse aspecto, será atribuído enfoque especial à doutrina Argentina pelo fato de ser responsável pelas primeiras manifestações acerca da carga dinâmica a partir dos estudos de Jorge W. Peyrano.

Após, será examinada a disposição trazida pelo CPC/2015 em seu art. 373, parágrafo primeiro, fazendo um paralelo com a previsão anteriormente contida no CPC/1973. A seguir, o trabalho seguirá para uma análise crítica do instituto, buscando inspiração na doutrina estrangeira, para fixar parâmetros adequados para a sua incidência. Feitas tais incursões, será examinada especificamente a aplicação da distribuição dinâmica do ônus da prova, nesses termos, ao Processo do Trabalho. 


\section{DO ÔNUS DA PROVA}

De acordo com Cândido Rangel Dinamarco, a prova é "o instrumento através do qual se forma a convicção do juiz a respeito da ocorrência ou inocorrência dos fatos controvertidos no processo" (DINAMARCO, 2005, p. 71).

Jorge Peyrano entende que a despeito da sua codificação tardia, o ônus probatório é verdadeiramente a espinha dorsal do processo civil (PEYRANO, 2013, p. 957-958). A carga probatória para Jorge Peyrano consiste em um imperativo do próprio interesse, cujo cumprimento implica em uma vantagem processual ou, ao menos, possibilita evitar uma desvantagem processual (PEYRANO, 2013, p. 957).

Giuseppe Chiovenda (2009) salienta que não há para as partes efetivo dever de produzir provas, mas sim um ônus, devendo a parte, na ausência da prova, suportar as consequências negativas decorrentes da não comprovação do fato alegado. Nesse sentido, pode-se dizer que o ônus da prova corresponde a um "encargo, atribuído pela lei a cada uma das partes, de demonstrar a ocorrência dos fatos de seu próprio interesse para as decisões a serem proferidas no processo" (DINAMARCO, 2005, p. 71).

Misael Montenegro Filho adota o mesmo entendimento, aduzindo que quando a lei atribui à determinada parte a responsabilidade pela produção da prova, "não sendo assumida a responsabilidade, a parte suporta consequências danosas, por vezes irremediáveis, considerando que a fase de instrução probatória é, sem qualquer dúvida, a mais importante do processo" (MONTENEGRO FILHO, 2016, p. 450).

Hernando Devis Echandía, seguindo linha semelhante, define a carga probatória, ressaltando sua importância para o julgador e para as partes envolvidas na lide como:

una noción procesal que contiene la regla de juicio por medio de la cual se le indica al juez cómo debe fallar cuando no encuentre en el proceso pruebas que le den certeza sobre los hechos que deben fundamentar su decisión, e indirectamente establece a cuál de las partes le interesa la 
prueba de tales hechos para evitarse las consecuencias desfavorables (DEVIS ECHANDIA, p. 426)

Peyrano acredita que a carga probatória é instrumento para contornar o fracasso da atividade probatória produzida pelas partes, evitando o insucesso de todo o processo civil (PEYRANO, 2013, p. 957). Segundo o autor:

\begin{abstract}
Señalábamos al principio que el tema que concita nuestra atención es la crónica del fracaso de la actividad probatoria, porque parte de la premisa de que las hipótesis afirmadas por los contradictores no han logrado reunir elementos de prueba suficientes para considerar que se está ante una versión aceptable. Por supuesto que "esa regla no puede entrar en juego cuando al menos una de las hipótesis sobre el hecho está dotada de un grado de confirmación probatoria suficiente para considerar que constituye una versión aceptable del hecho (PEYRANO, 2013, p. 958) .
\end{abstract}

O autor segue explicando que uma vez que o Judiciário não está autorizado a proferir um non liquet (sendo este um verdadeiro sinal de fracasso do processo civil) na incerteza sobre o fato em litígio, necessário é valer-se do ônus probatório para decidir-se o mérito ou, conforme o caso, proferir decisão de natureza interlocutória concernente a fatos que foram objeto de prova não suficiente para conferir certeza ao direito.

Para Peyrano, o ônus probatório não consiste em uma regra no campo das provas, mas sim em uma regra de julgamento, que muito além de repartir o ônus de comprovação entre as partes, reparte entre elas as consequências da ausência de prova ou da apresentação de prova insuficiente (PEYRANO, 2013, p. 959).

O autor explica seu posicionamento mais moderno afirmando que, na verdade, nem sempre a parte detentora do ônus é a que realiza a prova, que poderá ser produzida por iniciativa do próprio Juízo ou da parte adversa ao confessar de forma expressa ou tácita determinado fato. De todo modo, o risco da inexistência da prova será arcado pela parte detentora do ônus. 


\subsection{BREVE ANÁLISE DAS TEORIAS ACERCA DO ÔNUS DA PROVA}

Segundo o Direito Justiniano, incumbia a prova do fato à parte que o alegar. Sendo assim, se a defesa limitava-se a negá-lo, estaria dispensada de produzir qualquer prova. O mesmo entendimento perdurou durante a Idade Média, baseandose na máxima romana Ei incumbit probatio qui dicit, non qui negat (a prova incumbe a quem afirma e não a quem nega).

Chiovenda, de outro modo, repartiu entre as partes o ônus, conforme a qualificação dos fatos a serem provados. Entrega, assim, ao autor o ônus de provar os fatos constitutivos de seu direito e ao réu o ônus de provar os fatos impeditivos, modificativos e extintivos do direito pleiteado pelo autor. Já o juiz, na perspectiva de Chiovenda (2009), deveria se guiar, durante a instrução probatória, pelo princípio dispositivo, não cabendo a ele determinar a produção de quaisquer provas.

Para Chiovenda (2009) a repartição do ônus da prova estaria atrelada a um juízo de oportunidade. Isso porque ainda que seja razoável atribuir ao autor também a prova da inexistência de fatos impeditivos ou extintivos do seu direito, desenvolver essa atividade probatória Ihe seria impossível.

Além disso, para Chiovenda (2009), a repatição do ônus da prova estaria vinculada a um juízo de interesse, vez que as partes seriam responsáveis por produzirem as provas dos fatos que tenham aptidão para produzir o resultado que esperam alcançar no processo.

A despeito da teoria de Chiovenda ainda ser largamente utilizada em legislações que pouco disciplinaram o ônus da prova, Peyrano acredita que ela é insuficiente para resolver determinados litígios seja porque em alguns casos é difícil delimitar com clareza a natureza do fato a ser provado ou porque a parte autora formulou fatos de natureza impeditiva ou extintiva (PEYRANO, 2013, p. 961).

Carnelutti diverge de Chiovenda no que tange à ideia de atribuir a prova a quem tenha interesse no resultado. Para ele, ambas as partes possuem interesse na prova dos fatos afirmados no processo, seja para provar sua existência ou sua inexistência (CARNELUTTI, 2000, p.131). 
Para Carnelutti (2000) a composição justa da lide em caso de falta de provas estaria atrelada ao favorecimento da parte interessada na prova negativa em detrimento da parte a quem interessava produzir a prova positiva, ou seja, da existência do fato. O autor trata, assim, da ideia de risco a ser assumido pela ausência ou deficiência da prova.

Carnelutti, contudo, se aproxima da teoria de Chiovenda no que tange à atuação do juiz na produção da prova, estabelecendo que não lhe cabe buscar provas não trazidas aos autos pelas partes (CARNELUTTI, 2000, p. 134).

Leo Rosenberg sustentava que o ônus da prova cabe à parte a quem a norma favorece. Em outras palavras, o ônus da prova deve recair sobre a parte que somente pode lograr êxito no processo mediante a aplicação daquele determinado preceito jurídico (ROSENBERG, 2002).

A teoria traz consigo a dificuldade de determinar, então, quais normas favorecem o autor e quais favorecem o réu, pois somente a partir dessa premissa seria possível distribuir o ônus probatório.

Rosenberg acredita que as normas que favorecem o autor são aquelas que Ihe atribuem seu direito, assumindo a condição de base normativa da pretensão (isto é, normas constitutivas). De outro modo, ao réu caberia carrear ao processo provas capazes de implicar a improcedência do feito. Essas provas são concernentes aos fatos denominados por Rosenberg como impeditivos, destrutivos ou exclusivos do direito (muito próximos aos fatos impeditivos, extintivos e modificativos propostos por Chiovenda).

Micheli teria aprimorado a teoria proposta por Rosenberg ao afirmar que caberá o ônus probatório acerca de determinado fato à parte que pretender extrair de tal fato um efeito jurídico. Para o autor, o ônus da prova, determinaria a parte que deveria receber a decisão desfavorável.

Micheli (1961) disciplina a questão do ônus probatório a partir do que ele denomina como doutrina da decisão sobre feito incerto, que se encontra estabelecida em três premissas. A primeira delas é de que as partes possuem o poder de dispor de elementos materiais sobre o fato a partir do qual formula suas 
pretensões. A segunda e a terceira estão relacionadas ao julgador e estabelecem que é dever do juiz julgar conforme o que é alegado e provado nos autos do processo e, ainda, de decidir todos os casos a ele submetidos acolhendo ou rejeitando a pretensão (MICHELI, 1961, p. 104).

Para Peyrano as teorias propostas por Rosenberg e Micheli, muito embora apresentem certa vantagem comparativa, em muito se aproximam da proposta de Chiovenda já que:

Interpretamos que a pesar de contar con una presentación más pulcra y
científica, detrás de las propuestas de Rosenberg y Micheli reaparece, casi
sincambios, la vieja distribución chiovendiana. Vale decir que el peso de la
prueba a la luz de las teorías de Rosenberg y Micheli no se altera, en la
gran mayoría de los casos, cuando se aplica el venerable, pero todavía
usable, esquema chiovendiano38. Baste con memorar que dentro de la
teoría normativa de Rosenberg para que una norma pueda ser opuesta a
otra es indispensable que la primera comprenda la situación de hecho que
la segunda presupone, pero que contemple otros hechos capaces de
producir el efecto diferente. Obvio es que dicha oposición exige que
previamente se haya acreditado la concurrencia de los presupuestos
fácticos correspondientes. En que difiere, entonces, que se diga que se
pretende oponer una norma a otra de que se exprese que se opone un
hecho impeditivo o extintivo a otro constitutivo. De todas maneras, las
susodichas teorías presentan una indudable ventaja comparativa: resaltan
en mayor medida la relación existente entre la carga de afirmar y la carga
probatoria, aunque ambas no tengan una equivalencia
absoluta.(PEYRANO, 2013, p.961-962).

Michele Taruffo, de outro modo, propôs que deveria ser adotado um critério racional para escolher entre hipóteses fáticas opostas e aceitáveis. Tal critério corresponderia à probabilidade lógica prevalecente, que estaria baseada em se estabelecer em quais condições os elementos do juízo seriam suficientes para aceitar-se uma proposição como verdadeira (PEYRANO, 2013, p. 963).

Assim, diante de hipóteses contrárias, o mais adequado seria avaliá-las isoladamente para verificar qual delas apresentaria maior grau de confirmação, exercício este que não implicaria dizer que a outra hipótese é falsa, mas sim que ela apresenta menor grau de confirmação.

Taruffo se dedica, portanto, a racionalizar e objetivar, na medida do possível, a atuação do julgador na colheita da prova, estabelecendo que: 
Todo esto equivale a decir que el juez tiene el deber preciso de extraer, de su contacto directo con la prueba, los factores epistémicamente aceptables. A continuación, sobre la base de estos "datos", debe construir renferencias, fundadas sobre reglas o estándares de valoración que deben ser claramente identificables, sobre todo por el proprio juez que los usa. En cierto sentido, lo que no puede ser racionalmente elaborado no existe a los efectos de la correcta valoración de la prueba (TARUFFO, s.d, p. 84).

Todas as teorias então propostas, embora muito ricas em variados aspectos, por terem natureza tipicamente estática, não são suficientes para se adequar à riqueza dos casos particulares. Nessa perspectiva, ganha relevância outras propostas mais flexíveis e adaptáveis às exigências dos casos concretos como a da distribuição dinâmica do ônus da prova.

\subsection{DISTRIBUIÇÃO DINÂMICA DO ÔNUS DA PROVA: UMA ANÁLISE DA PROPOSTA DE JORGE W. PEYRANO}

A distribuição dinâmica do ônus probatório consiste em uma possibilidade de alterar as regras estáticas de distribuição do ônus probatório de forma a atribuir, em situações específicas, o ônus de provar àquele que inicialmente não o possuiria. Isso se dá em situações em que a outra parte apresenta melhores condições ou mais aptidão para comprovar certo fato.

Segundo Peyrano, a distribuição dinâmica do ônus probatório:

se traduce en que frente a situaciones excepcionales que dificultan la tarea probatoria de una de las partes, se debe desplazar el esfuerzo probatorio respectivo hacia la contraria, por encontrarse ésta en mejores condiciones de acreditar algún hecho o circunstancia relevante para la causa (PEYRANO, 2013, p. 971).

É de se dizer que a distribuição dinâmica não equivale à inversão do ônus da prova, vez que não é seu objetivo determinar que uma das partes deva assumir inteiramente o ônus de provar todos os fatos atinentes à pretensão da parte adversa. 
Peyrano explica o fato citando o caso da distribuição dinâmica do ônus probatório em caso de erro médico, situação em que caberia ao médico e não ao paciente produzir provas acerca da regularidade ou não do procedimento técnico adotado. Isso se daria em razão da sua melhor aptidão para produzir esta prova. Demais nuances do caso, como a realização do procedimento em data e local específicos, permaneceria devendo ser comprovadas pela parte autora (PEYRANO, 2013, p. 971).

Segundo Peyrano:

\begin{abstract}
Por supuesto que el desplazamiento atípico del onus probandi que importa la aplicación de la doctrina de las cargas probatorias dinámicas, funciona, de ordinario, respecto de determinados hechos o circunstancias y no de todo el material fáctico. Ello implica que tal aplicación no acarrea un desplazamiento completo de la carga probatoria, sino tan sólo parcial; conservándose en cabeza de la otra parte la imposición de ciertos esfuerzos probatórios (PEYRANO, 2013, p. 972).
\end{abstract}

Para viabilizar o emprego da distribuição dinâmica do ônus probatório, o autor propõe, na ausência de previsão legislativa, a aplicação, dentre outras técnicas, do princípio da cooperação processual. Nessa medida, como o dever de produção de provas seria compartilhado entre as partes, sua distribuição deveria ser guiada pela aptidão para a sua produção. No entanto, essa preocupação não mais aflige os juristas brasileiros, foco desta análise, já que o Código de Processo Civil Brasileiro de 2015 recebe expressamente a teoria em seu art. 373, parágrafo primeiro.

\title{
2 A DISTRIBUIÇÃO DINÂMICA DO ÔNUS DA PROVA NO CÓDIGO DE PROCESSO CIVIL BRASILEIRO DE 2015
}

A distribuição clássica do ônus da prova conforme o Código de Processo Civil de 1973 consubstanciava uma noção estática da distribuição do ônus probatório. O art. 333 do CPC/1973 dispunha caber ao autor a prova dos fatos constitutivos do seu direito e ao réu era atribuído o ônus de provar fatos impeditivos, modificativos ou extintivos do direito do autor. Era a sua literalidade: 


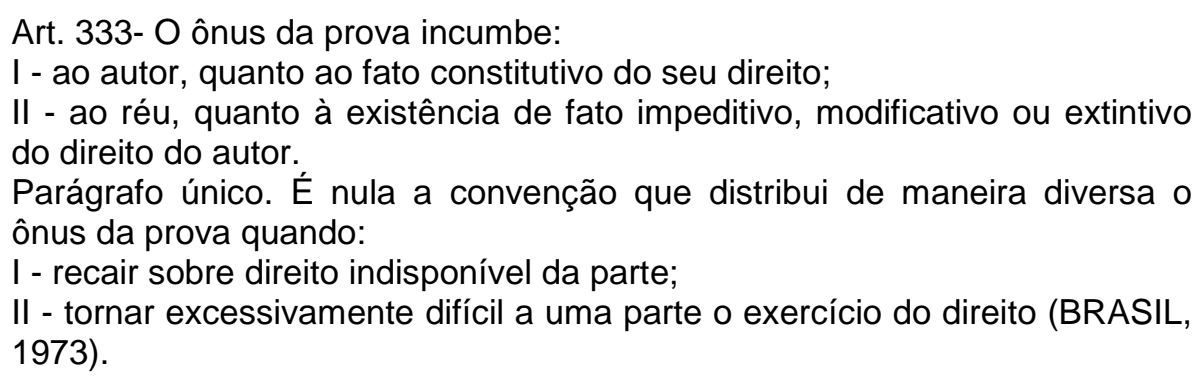

Pode-se afirmar, assim, que a distribuição do ônus da prova, nos termos estabelecidos pelo CPC de 1973, tinha natureza imutável, admitindo-se somente as hipóteses legais, sem que pudesse sofrer qualquer tipo de adaptação a partir das necessidades impostas pelo caso concreto.

É de se considerar que a concepção clássica e estática da distribuição do ônus da prova adotada pelo Código de Processo Civil de 1973 não se coaduna com o modelo constitucional brasileiro do processo civil, vinculado à noção de justiça processual, ou seja, de realização da justiça por meio do processo judicial.

A teoria estática sobre o ônus probatório possui, assim, a tendência de promover a inefetividade da tutela, vez que não raro atribui o ônus probatório à parte hipossuficiente no processo. O emprego de regras rígidas acerca da distribuição do ônus da prova acarreta ainda a inércia do julgador, o que, por sua vez, potencializa o risco de erros e de injustiças (LOURENÇO, 2016).

O Código de Processo Civil de 2015 acolheu, sem seu art. 373, a regra geral de distribuição do ônus da prova prevista no art. 333 do Código Processual anterior, entregando ao autor o dever de comprovar os fatos constitutivos de seu direito e ao réu, os fatos impeditivos, modificativos e extintivos do direito.

Muito embora tenha adotado do código anterior o elemento básico do sistema estático de distribuição do ônus da prova, inovou ao possibilitar em seu parágrafo primeiro que o juiz distribua o ônus de forma diferenciada conforme se demonstrar necessário no caso concreto. Nesse aspecto, recebeu a teoria da carga dinâmica da prova.

Segundo Montenegro Filho: 
Por tradição, nosso direito processual sempre adotou a teoria estática de distribuição do ônus da prova, marcada pela distribuição imutável do ônus da prova, obrigando a quem alega o fato prová-lo. Contudo, a teoria estática não é adequada para resolver os casos de prova diabólica ou negativa. Por conta disso, foi desenvolvida a teoria da distribuição dinâmica do ônus da prova, fundada no princípio da igualdade ou da isonomia, atribuindo o ônus da prova a quem puder suportá-lo, ideia que marca o novo CPC (MONTENEGRO FILHO, 2016, p. 452).

É a literalidade do art. 373 do CPC:

Artigo $373 \mathrm{O}$ ônus da prova incumbe:

I - ao autor, quanto ao fato constitutivo de seu direito;

II - ao réu, quanto à existência de fato impeditivo, modificativo ou extintivo do direito do autor.

$\S 1^{\circ}$ Nos casos previstos em lei ou diante de peculiaridades da causa relacionadas à impossibilidade ou à excessiva dificuldade de cumprir o encargo nos termos do caput ou à maior facilidade de obtenção da prova do fato contrário, poderá o juiz atribuir o ônus da prova de modo diverso, desde que o faça por decisão fundamentada, caso em que deverá dar à parte a oportunidade de se desincumbir do ônus que lhe foi atribuído.

$\S 2^{\circ}$ A decisão prevista no $\S 1^{\circ}$ deste artigo não pode gerar situação em que a desincumbência do encargo pela parte seja impossível ou excessivamente difícil.

$\S 3^{\circ}$ A distribuição diversa do ônus da prova também pode ocorrer por convenção das partes, salvo quando:

I - recair sobre direito indisponível da parte;

II - tornar excessivamente difícil a uma parte o exercício do direito.

$\S 4^{\circ} \mathrm{A}$ convenção de que trata o $\S 3$ o pode ser celebrada antes ou durante 0 processo. (BRASIL, 2015).

Ao admitir que o juiz fundamentadamente altere a distribuição clássica do ônus da prova quando as peculiaridades da causa o exijam ou, ainda, quando haja impossibilidade ou excessiva dificuldade para que a parte produza a prova, o CPC de 2015 acolhe uma perspectiva flexível ou dinâmica da repartição do ônus. Nesses termos, pode-se dizer que o código admite que em situações excepcionais e justificadas o ônus seja suportado pela parte que, consoante as particularidades do caso concreto, demonstra melhores condições para provar os fatos, isto é, de colaborar para o alcance da verdade. Dessa maneira, caberá ao juiz determinar a quem será entregue a responsabilidade pela produção da prova e consequentemente o ônus da sua ausência. 
Nessa perspectiva de modificação pelo julgador do esquema clássico da prova, nem sempre será obrigação do autor provar os fatos constitutivos do seu direito e, igualmente, nem sempre será do réu o ônus dos fatos modificativos, impeditivos ou extintivos da pretensão do autor.

Impende ressaltar que o parágrafo $2^{\circ}$ do artigo 373 , veda a distribuição do ônus da prova nos casos em que a produção da prova se torne impossível ou extremamente difícil à parte, isto é, as chamadas provas diabólicas.

É importante mencionar que além da possibilidade de modificação da responsabilidade pela prova por meio de decisão judicial, o Código de Processo Civil também permite que a distribuição diversa do ônus da prova se dê por acordo das partes, exceto quando incidir sobre direito indisponível ou quando a modificação do ônus tornar o exercício do direito excessivamente difícil.

Essa regra parece ter sido criada a partir da ideia de cooperação processual que o Código de Processo reformado impõe às partes em seu art. $6^{\circ}$ ao aduzir que "Todos os sujeitos do processo devem cooperar entre si para que se obtenha, em tempo razoável, decisão de mérito justa e efetiva".

Sérgio Cruz Arenhart, em Simpósio realizado pela ENAMAT e destinado a discutir as repercussões do novo CPC no direito processual trabalhista, ainda projetado naquele momento, comenta sobre a inadequação da perspectiva estanque para a distribuição do ônus da obra na perspectiva do dever de cooperação:

\footnotetext{
Logo, quem supõe a existência de um dever geral de colaboração, fixado como de fato está fixado no Código de Processo Civil, dificilmente tem como lidar com a ideia de ônus de prova como regra de procedimento. Por quê? Porque percebe se todos têm o dever de colaborar, não posso dizer que é o autor que tem que provar o fato "a", e o réu que tem que provar o fato "b", porque todos têm que provar o fato "a" e o fato "b", se tiver condições de fazer prova daquele fato. Essa é a perspectiva que acho fundamental (ARENHART, 2014, p.111).
}

A despeito da adequação da medida no que tange à consecução de importantes valores processuais, a redistribuição da carga probatória exige cautela e análise acurada por parte do julgador de forma a impedir que sua adoção possa 
romper com o equilíbrio processual, sobrecarregando uma das partes no momento da instrução.

\section{VISÃO CRÍTICA ACERCA DA CARGA DINÂMICA DA PROVA: DA DESNECESSIDADE DE SUA PREVISÃO À SUA APLICAÇÃO CONSTITUCIONALMENTE ORIENTADA}

Diego Palomo Vélez ${ }^{2}$ acredita que a carga dinâmica da prova compromete o direito de defesa e a segurança jurídica. $O$ autor examina algumas propostas, concluindo ser desnecessário e inadequado prever normativamente a possibilidade de alteração da carga probatória.

Vélez cita a proposta que se sustenta na necessidade de o juiz avisar as partes em audiência preliminar de sua decisão quanto à modificação do ônus da prova, permitindo que, a partir desse momento, dele se desincumbam. Para esse autor, a declaração da modificação da carga probatória em sentença inviabilizaria o adequado exercício do direito de defesa e o contraditório. Contudo, acredita que o aviso em audiência preliminar também não garante tempo hábil para a produção da prova. Avalia, por essa razão, outras possíveis soluções.

Segundo Vélez:

Se propone, entonces, asumir una fórmula que asociada al neoprocesalismo, en esta versión, está profundamente marcada por la subjetividad de los criterios que le sirven de orientación y la discrecionalidad judicial en que se permite su concreción que, en algunos países (como acontece en la propia Argentina, también en Uruguay), termina materializando un modelo de juez decisionista y un modelo de proceso que no sólo afecta negativamente la seguridad jurídica, sino también el derecho de defensa y el principio del contradictorio a partir de la permisividad con la sorpresa de la definición judicial de última hora르. Este judicialismo del caso concreto de generación sin sustento legal ha sido objeto de críticas también por autores reconocidamente partidarios de un reforzado protagonismo de los jueces, destacando los problemas que genera frente a la debida imparcialidad judicial y reconociendo la significativa dificultad de autorizar a los jueces un poder discrecional para manipular la carga probatoria de un modo diverso al contemplado por la leyֵㅗ, peor aún cuando dicha manipulación judicial sólo

${ }^{2} \mathrm{O}$ autor direciona sua análise para a realidade chilena. 
se produce al momento de dictar la sentencia 30 , cuando la parte a la cual se le hace soportar la carga redistribuida ya no puede probar (VÉLEZ, 2013, p.457-458).

Diego Vélez reconhece que o tema envolve uma problemática questão em torno da colaboração entre as partes em matéria probatória. Não se olvide que são partes adversas e colaborar com a parte contrária, seria produzir prova contra si ${ }^{3}$.

Para o autor, seria suficiente prever normativamente a possibilidade de solicitar em juízo, mediante fundamentação verossímil, que a outra parte seja compelida a apresentar determinada prova que esteja em sua posse ou cuja apresentação the seja mais simples. E, em caso de não apresentação injustificada da prova solicitada pela parte adversa e determinada pelo juiz deveria ser imposta a consequência processual negativa de presumirem-se verdadeiras as alegações da parte que solicitou a apresentação da prova de dado fato. Esse efeito, contudo, não se aplicaria caso as demais provas do caso apontassem para uma conclusão distinta (VÉLEZ, 2013).

Nesse caso, segundo Vélez, não haveria modificação do ônus original de produção da prova, mas sim atribuição à parte adversa de um ônus de contraproduzir a presunção aplicada em razão de sua conduta processual.

Juan Carlos Diaz-Restrepo (2016), adota entendimento diverso ao analisar criticamente a reforma empreendida no ordenamento colombiano em matéria probatória, destacando que, apesar de reconhecer a pertinência das alterações empreendidas, vislumbra na carga dinâmica da prova um risco à igualdade processual caso não haja o devido cuidado em sua aplicação.

O Código Geral de Processo ${ }^{4}$ colombiano passou a admitir a modificação pelo juiz do ônus da prova quando uma das partes está mais próxima do material da

\footnotetext{
${ }^{3}$ Nas palavras do autor: "Al respecto, de inmediato debemos consignar, por obvio que resulte, que no es realista aspirar a que las partes (sus abogados) incorporen al proceso pruebas que les perjudiquen y favorezcan a la contraria: no sólo es impropio de la naturaleza humana, sino que iría contra del deber profesional del abogado con su cliente. El abogado debe luchar y defender la posición jurídica de su cliente haciendo uso de todas las herramientas legales" (VÉLEZ, 2013, p. 460).

${ }^{4}$ É a redação do art. 167 do Código Geral Colombiano: "Artículo 167. Carga de la prueba. Incumbe a las partes probar el supuesto de hecho de las normas que consagran el efecto jurídico que ellas
} 
prova ou o tem em seu poder, apresenta melhor capacidade técnica para fazê-lo, houver intervindo diretamente nos fatos que motivaram o litígio ou quando a parte que seria responsável pela prova encontra-se indefesa ou em situação de incapacidade para fazê-lo, além de outras situações similares.

Analisando a questão sob o ponto de vista da igualdade, Diaz-Restrepo salienta a necessidade de demonstrar-se a existência dos requisitos postos pela Corte Constitucional Colombiana como justificativa para tratamentos diferenciados a fim de realização do ideal de igualdade, evitando-se arbitrariedade: justificativa objetiva e razoável, proporcionalidade e razoabilidade. Segundo o autor:

\begin{abstract}
Ciertamente, cuando el artículo 167 del Código General del Proceso plantea que: incumbe a las partes probar el supuesto de hecho de las normas que consagran el efecto jurídico que ellas persiguen y posteriormente le otorga la posibilidad al juez de que en atención a las particularidades del caso distribuya entre las partes la carga de la prueba- lo que en esencia está instituyendo es la posibilidad para que el juez adopte una medida de tratamiento desigual a las partes implicadas en el proceso, las cuales por regla general se reputan en igualdad de condiciones y derechos. Tal tratamiento desigual consiste en la creación de un privilegio procesal exención parcial o total de la carga probatoria de una de las partes en atención a la mejor posición para probar de la contraparte, a la que correlativamente se impone total o parcialmente tal carga- basada en el derecho a la igualdad y más concretamente en su mandato de diferenciación, en tal sentido debe cumplir con los requisitos relativos a las medidas de diferenciación que ha sentado la Corte Constitucional para que esta sea válida y no se viole con ella el derecho a la igualdad, a saber, a) Justificación objetiva y razonable b) Proporcionalidad c) Racionalidad.( DiazRestrepo, 2016, p. 213).
\end{abstract}

De acordo com Diaz-Restrepo a justificativa para a dinamização da carga probatória consistiria na existência de processos judiciais em que, por motivos

persiguen. No obstante, según las particularidades del caso, el juez podrá, de oficio o a petición de parte, distribuir la carga al decretar las pruebas, durante su práctica o en cualquier momento del proceso antes de fallar, exigiendo probar determinado hecho a la parte que se encuentre en una situación más favorable para aportar las evidencias o esclarecer los hechos controvertidos. La parte se considerará en mejor posición para probar en virtud de su cercanía con el material probatorio, por tener en su poder el objeto de prueba, por circunstancias técnicas especiales, por haber intervenido directamente en los hechos que dieron lugar al litigio, o por el estado de indefensión o de incapacidad en la cual se encuentre la contraparte, entre otras circunstancias similares. Cuando el juez adopte esta decisión, que será susceptible de recurso, otorgará a la parte correspondiente el término necesario para aportar o solicitar la respectiva prueba, la cual se someterá a las reglas de contradicción previstas en este código [...]" 
diversos, há graves desequilíbrios no que tange à prova do que alegam. Nesse caso, redistribuir a carga probatória seria tratar desigualmente as partes em razão de tal disparidade como efetivo meio de alcance da igualdade processual. No entanto, para o autor, a existência de tal justificativa não seria suficiente para a alteração empreendida no campo probatório, pois ela necessita estar dotada de objetividade.

Diaz-Restrepo concebe a objetividade da justificativa de dois modos distintos. O primeiro deles está no campo da finalidade, que transcende o interesse social. Consistiria no objetivo de buscar um garantismo processual capaz de salvaguardar os direitos fundamentais e a própria aplicação da justiça, dando concretude ao Estado social (DIAZ-RESTREPO, 2016, p. 214).

Contudo, em sua segunda acepção, de natureza individual, a objetividade da justificativa estaria comprometida segundo Diaz-Restrepo. Nessa perspectiva, a justificativa para a alteração do ônus em razão de uma das partes apresentar melhores condições ou aptidão não seria suficiente. Na verdade, a modificação, para o autor, só estaria autorizada nesses casos se estivesse caracterizado um claro desequilíbrio entre as partes:

El legislador ha considerado erróneamente que la verificación de alguna de las hipótesis de hecho que integran el concepto de mejor posición para probar da -por sí sola- lugar válidamente a que proceda la distribución de las cargas probatorias, no siendo así. Cuando la intención de la norma es atender a los desequilibrios que puedan existir entre las partes debe asegurarse de recaer sobre una situación en la que efectivamente existan tales desequilibrios, pero las hipótesis de hecho aludidas no prestan tal seguridad. Una cosa es que una de las partes esté en mejor posición para probar en virtud de su cercanía con el material probatorio, por tener en su poder el objeto de prueba, por circunstancias técnicas especiales, por haber intervenido directamente en los hechos que dieron lugar al litigio, o por el estado de indefensión o de incapacidad en el cual se encuentre la contraparte ; y otra cosa, bien distinta, es que efectivamente la existencia de alguna de tales circunstancias en el caso concreto ocasione un desequilibrio y que este sea de tal entidad que justifique la aplicación de la regla de carga dinámica de la prueba, es decir, de la medida de diferenciación (DIAZRESTREPO, 2016, p. 214). 
Quanto à razoabilidade, o autor salienta que está consubstanciada nos ideais de conveniência e necessidade que, por sua própria natureza, somente podem ser aferidos pelos próprios juízes dentro da sutileza de cada caso concreto. Não são, portanto, um dado, mas situações a serem avaliadas em cada demanda. A Corte Constitucional Colombiana teria estabelecido como parâmetros a existência de justiça, equidade e prudência na aplicação da medida. Dessa forma, a carga dinâmica seria dotada de razoabilidade se fosse medida conveniente e necessária para evitar a violação de direitos, resguardando os interesses de ambas as partes na maior medida possível (DIAZ-RESTREPO, 2016, p. 215).

A proporcionalidade, por sua vez, estaria na relação harmônica entre esses elementos: a constatação pelo julgador da existência de real desequilíbrio no campo probatório e da conclusão pela aptidão da medida para evitar a violação de direitos e para melhor salvaguardar o interesse de ambas as partes, além de propiciar um garantismo processual dos direitos fundamentais. Nas palavras do autor:

\begin{abstract}
Sumado a que como se advirtió, es un análisis que involucra la conciencia del operador judicial y los raciocinios que estime conveniente realizar conforme a la realidad particular y concreta de las partes involucradas en la litis, aquí, sin embargo, vale decir que el requisito se cumple cuando exista una relación de proporcionalidad y racionalidad entre: (i) la justificación objetiva y razonable, sobre el establecimiento del trato diferenciador, autorizado por el artículo 167 del Código General del Proceso, referido que es la existencia de una situación de desequilibrio real y efectivo en el caso concreto al cual se aplica y en virtud del cual sea determinante el establecimiento de tal trato ante la inminencia de afectación de derechos; (ii) los hechos, que dependen de la situación en concreto y finalmente, (iii) el fin que se persigue, constitucionalmente legítimo y que constituye el de la protección de la igualdad material a que tiene derecho toda persona, más la máxima de que la verdad sea vinculada efectivamente al proceso.

Cabe aclarar que la racionalidad se refiere a la coherencia que debe existir entre estos elementos, que vinculados por preceptos lógicos y no contradictorios además respondan al sentido común y a la razón. Mientras que la proporcionalidad sea fundada sobre la base de que entre estos elementos exista una relación armónica que, sin menoscabar la importancia de algunos de ellos, eleve la resonancia de alguno otro cuando la equidad lo haga imperioso (DIAZ-RESTREPO, 2016, p. 215-216).
\end{abstract}

Diante de tais elementos, Diaz-Restrepo adverte que o artigo 167 do Código Colombiano ao permitir a alteração do ônus probatório pelo juiz sem estabelecer 
normativamente critérios para que haja justificativa objetiva e razoável para a sua aplicação, assume feição inconstitucional, contrariando premissas como o devido processo legal e a garantia de igualdade entre as partes. No entanto, sua adequada aplicação em nada violaria o texto constitucional.

O autor, portanto, ressalta que não se cogitar declarar a norma inscontitucional, retirando-a do sistema, pois essa medida consistiria em efetivo retrocesso. Para Diaz-Restrepo a previsão da carga dinâmica da prova tem um fim legítimo e garantista, sendo necessário dar-lhe uma solução jurídica capaz de garantir que sua aplicação não viole, mas sim realize as máximas constitucionais.

Diaz-Restrepo sugere, então, que a norma seja dotada de maior clareza quanto aos exercícios a serem realizados pelo juiz dentro do processo antes de decidir pela modificação do ônus da prova. Entre eles, mencionados pelo autor como princípios, estão a existência real e efetiva de um desequilíbrio a exigir a modificação como forma de evitar a violação de direitos e a proporcionalidade entre o desequilíbrio existente no caso concreto e a diferenciação estabelecida pelo julgador ${ }^{5}$.

\section{A DISTRIBUIÇÃO DINÂMICA DO ÔNUS DA PROVA E O DIREITO PROCESSUAL DO TRABALHO}

A Consolidação das Leis do Trabalho, em seu artigo 818, adota parâmetro similar ao do artigo 333 do Código de Processo Civil de 1973, embora de

\footnotetext{
${ }^{5}$ A esse respeito o autor explica: "Guardar las proporciones en aplicación de la regla de carga dinámica de la prueba es necesario para no ocasionar un contrasentido de la figura pues como se expresó, esta constituye un arma de doble filo que exige que en aplicación del beneficio a favor de una de las partes por considerarse que se halla en posición desventajosa de la relación procesal, no se vayan a invertir los papeles sino que se asegure el restablecimiento de la igualdad material. En atención a este principio se debe dar al juez la posibilidad para, que interrogue exhaustivamente a las partes a fin de hallar la justa intensidad de la diferenciación y la cuota optima de distribución. Y se le debe imponer también la exigencia de que motive ampliamente la decisión que adopte de distribuir las cargas tanto, cuando se profiera como consecuencia de su iniciativa oficiosa o cuando se profiera como consecuencia de la solicitud de parte. A esta misma exigencia deberá estar sometida la decisión que niegue la solicitud de distribución de las cargas probatórias" (DIAZ-RETREPO, 2016, p. 217).
} 
modo mais objetivo, atribuindo o ônus de provar os fatos à parte que os alegar. Nessa ordem de ideias, caberia ao réu, provar os fatos impeditivos, modificativos ou extintivos que suscitar na intenção de obter a improcedência em relação aos pedidos formulados pelo autor.

O caráter rígido e estático da norma, no entanto, vem sendo amenizado, na medida em que a incidência do princípio da proteção, norte do direito laboral, tem motivado a jurisprudência trabalhista a flexibilizar o ônus probatório, entregando-o ao reclamado quando a prova do direito do reclamante se demonstrar demasiadamente difícil ou até mesmo impossível em razão de sua subordinação contratual.

Vale salientar que normalmente as provas de natureza documental se encontram em poder do patrão. Além disso, as provas testemunhais não raro são prejudicadas quanto à sua fidedignidade em virtude da relação de emprego por vezes ainda vigente com o patrão, reclamado na demanda.

Muito embora a carga dinâmica do ônus probatório muito se aproxime da própria lógica do direito do trabalho, inexiste previsão normativa específica da medida para este ramo juslaboral. O que há até o momento são súmulas que tratam de situações pontuais a exemplo das súmulas 6, 338, 443, 460 e 461 do TST. De todo modo, muito embora não haja disposição expressa na legislação laboral acerca da possibilidade de modificação do ônus da prova, o advento do Código de Defesa do Consumidor já permitia ao juiz do trabalho a aplicação da inversão do ônus da prova em situações específicas, dando concretude ao inciso VIII do art. 6ำ do CDC em demandas laborais ${ }^{6}$.

De todo modo, após a introdução da regra da carga dinâmica do ônus da prova no CPC de 2015, o julgador encontra clara autorização para melhor distribuir o ônus probatório, mediante aplicação do art. 373 do CPC, incidência esta permitida pelos artigos $8^{\circ}$ e 769 da CLT. Isso porque o art. $8^{\circ}$, em seu parágrafo único,

\footnotetext{
${ }^{6} \mathrm{O}$ art. $6^{\circ}$ do Código de Defesa do Consumidor estabelece que "São direitos básicos do consumidor: [...] VIII - a facilitação da defesa de seus direitos, inclusive com a inversão do ônus da prova, a seu favor, no processo civil, quando, a critério do juiz, for verossímil a alegação ou quando for ele hipossuficiente, segundo as regras ordinárias de experiências".
} 
estabelece que "O direito comum será fonte subsidiária do direito do trabalho, naquilo em que não for incompatível com os princípios fundamentais deste" e, também, o art 769, que versa sobre o processo judiciário do trabalho, dispõe que "Nos casos omissos, o direito processual comum será fonte subsidiária do direito processual do trabalho, exceto naquilo em que for incompatível com as normas deste Título". Na mesma linha, o art. 15 do CPC de 2015 disciplina que na ausência de normas trabalhistas específicas admite-se a aplicação supletiva e subsidiária de suas disposições.

Vale ressaltar ainda que a Instrução Normativa n. 39 editada pelo Tribunal Superior do Trabalho com o fim de disciplinar as regras processuais civis constantes do CPC de 2015 aplicáveis ao processo trabalho, dispõe em seu art. 3ํ, VII, que se aplica aos processos trabalhistas o disposto nos parágrafos primeiro e segundo do art. 373, autorizando, portanto, a distribuição dinâmica do ônus da prova pelo julgador. No entanto, no que tange ao disposto nos parágrafos $3^{\circ}$ e $4^{\circ}$ do art 373 , a Instrução Normativa n. 39 , em seu art. $2^{\circ}$, VII, nega sua aplicabilidade aos processos de cunho laboral, estando, portanto, rejeitada a possibilidade de modificação do ônus probatório por meio de acordo entre as partes.

A expressa permissão da aplicação da regra da distribuição dinâmica ao processo laboral vem eliminar qualquer discussão acerca da impossibilidade de sua incidência na seara laboral em razão de a CLT tratar da matéria do ônus probatório em seu art. 818, inexistindo lacuna. É de se considerar que o caráter dinâmico da prova apresenta clara aptidão para promover a ideia de efetividade processual tão cara nos processos laborais, motivo pelo qual a regra civilista se amolda aos seus princípios fundamentais. Esse é o entendimento Mauro Schiavi:

Diante da necessidade de se dar efetividade ao acesso à ordem jurídica justa e não inviabilizar a tutela do direito à parte que tem razão, mas não apresenta condições favoráveis de produzir a prova do fato constitutivo de seu direito, é possível o juiz do trabalho atribuir o encargo probatório à parte que detém melhor condição de produzir a prova. É o que a doutrina tem chamado de carga dinâmica na produção do ônus da prova (SCHIAVI, 2017, p. 733). 
De forma semelhante, invocando a ideia de igualdade e de justiça distributiva, Carlos Alberto Reis de Paula trata da ideia (ou princípio) da aptidão para prova, demonstrando sua pertinência aos litígios de natureza laboral:

O fundamento para a aplicação do princípio da aptidão está na justiça distributiva aliada ao princípio da igualdade, cabendo a cada parte aquilo que normalmente lhe resulta mais fácil. $O$ critério será o da proximidade real e de facilidade do acesso às fontes de prova. Indiscutivelmente, o princípio será aplicado todas as vezes em que o empregado não pode fazer a prova a não ser através de documento ou coisa que a parte contrária detém (PAULA, 2001, p. 143).

\section{CONCLUSÃO}

O emprego da regra estática de distribuição do ônus probatório engessa a atuação jurisdicional, privando o Judiciário de meios que garantam a imposição de decisões mais adequadas em situações que, de um lado, a parte requerente não dispõe de meios de provar o direito e, de outro, a parte requerida tem acesso ao material probatório com razoável facilidade. O dinamismo da vida requer da lei e do julgador certa flexibilidade para captar as especificidades dos casos concretos a exigir adaptações da regra geral e abstratamente posta.

A medida se coaduna com as ideias de efetividade processual e de cooperação entre os sujeitos do processo, devendo-se dar primazia à busca da verdade e não a adoção de uma regra geral de julgamento a ser adotada de forma a evitar o non liquet.

Nessa perspectiva, a consagração da distribuição dinâmica do ônus da prova no parágrafo primeiro do art. 373 vem permitir ao julgador adaptar o esquema estático da prova em caso de impossibilidade ou excessiva dificuldade no cumprimento do encargo e, ainda, de maior facilidade de obtenção da prova do fato contrário. Essa iniciativa já vinha sendo aplicada pelo Judiciário Trabalhista, que buscava amparo doutrinário para a adoção da medida. A previsão expressa, cuja 
aplicação ao processo laboral está autorizada pela Instrução Normativa n. 39, vem, contudo, eliminar possíveis resistências à sua incidência.

Vale ressaltar, no entanto, que não se trata de permissão para a inversão completa do ônus da prova, mas sim da possibilidade de alterar a distribuição clássica do ônus para alguns fatos específicos, impondo à outra parte o dever da prova. Mantem-se, contudo, o esquema estático e tradicional do ônus probatório quanto aos demais fatos cuja prova não seja impossível ou excessivamente difícil para a parte responsável pela mesma.

No entanto, há que se aplicar o instituto com prudência, de forma a evitar sua aplicação irrestrita e, assim, violar outras garantias processuais. Há que se verificar se, de fato, a prova é impossível ou excessivamente difícil ou se há maior facilidade na obtenção da prova do fato contrário, evidenciando claro desequilíbrio entre as partes em matéria probatória.

A medida da alteração do ônus probatório pelo julgador deve funcionar como mecanismo apto a evitar a violação de direitos em razão do desequilíbrio existente no campo probatório e para melhor salvaguardar o interesse de ambas as partes do processo, garantindo que este seja efetivo sem que seja necessário alijar das partes as faculdades inerentes ao devido processo legal, ao contraditório e a ampla defesa.

\section{REFERÊNCIAS}

ARENHART, Sérgio Cruz. Ônus da prova. Palestra proferida na Escola Nacional de Formação e Aperfeiçoamento de Magistrados do Trabalho - ENAMAT, no dia 15 de setembro de 2014, às 17h10. Transcrição realizada pela Divisão de apoio e registro taquigráfico do TST. Revisão final do texto pela assessoria da Direção da ENAMAT. Disponível em:< http://www.enamat.jus.br/wpcontent/uploads/2014/09/Degrava\%C3\%A7\%C3\%A3o-do-

Simp\%C3\%B3sio CPC.pdf.> Acesso em 20 out. 2017

CARNELUTTI, Francesco. Sistema de Direito Processual Civil. Trad. Hiltomar Martins Oliveira. São Paulo: Classicbook, 2000.

CHIOVENDA, Giuseppe. Instituições de Direito Processual Civil. Trad. Paolo Capitanio. Campinas: Bookseller, 4. ed., 2009. 
DEVIS ECHANDÍA, Hernando. La teoría general de la prueba judicial. Editorial Víctor de Zavalía, T. I,

DIAZ-RESTREPO, Juan Carlos. La carga dinámica de la prueba como modalidad de carga probatoria aplicada en el ordenamiento jurídico colombiano. Vulneración a la igualdad constitucional. Entramado, Cali, v. 12, n. 1, p. 202-221, June 2016. Available from <http://www.scielo.org.co/scielo.php?script=sci_arttext\&pid=S1900$38032016000100014 \& \operatorname{lng}=$ en\&nrm $=$ iso $>$. access on 15 Oct. 2017.

http://dx.doi.org/10.18041/entramado.2016v12n1.23123.

DINAMARCO, Cândido Rangel. Instituições de Direito Processual Civil. V. III. São Paulo: Malheiros, 5 ed., 2005, p. 71.

LOURENÇO, Haroldo. Teoria dinâmica do ônus da prova no novo CPC. Rio de Janeiro: Ed. Forense, 2015.

MICHELI, Gian Antonio. La carga de la prueba. Trad. Santiago Sentis Melendo. Buenos Aires: Ejea, 1961.

MONTENEGRO FILHO, Misael. Curso de Direito Processual Civil: de acordo com novo CPC. 12 ED. REFORM. E ATUAL. São Paulo: Atlas, 2016.

PALOMO VELEZ, Diego. LAS CARGAS PROBATORIAS DINÁMICAS: ¿ES INDISPENSABLE DARSE TODA ESTA VUELTA?. Ius et Praxis, Talca, v. 19, $\mathrm{n}$. 2, p. 447-466, 2013 . Disponible en <http://www.scielo.cl/scielo.php?script=sci_arttext\&pid=S0718$00122013000200015 \&$ Ing=es\&nrm=iso $>$. accedido en 15 oct. 2017. http://dx.doi.org/10.4067/S0718-00122013000200015.

PAULA, Carlos Alberto Reis de. A especificidade do ônus da prova no processo do trabalho. São Paulo: LTR, 2001, p. 143.

PEYRANO, Jorge W. La carga de la prueba. In: Escritos sobre diversos temas de Derecho Procesal. 2013 Disponível em:

<https://letrujil.files.wordpress.com/2013/09/38jorge-w-peyrano.pdf>. Acesso em: 13 out. 2017.

PEYRANO, Jorge W. Las cargas probatórias dinâmicas, hoy. 2016. Disponível em: < http://faeproc.org/wp-content/uploads/2016/02/Rosario_34.pdf > . Acesso em: 13 out. 2017.

ROSENBER, Leo. La Carga de la Prueba. Trad. Ernesto Krotoschin. Buenos Aires: Julio Cesar Faria, 2002. 
SCHIAVI, Mauro. Manual de direito processual do trabalho. 12ed. São Paulo: LTr, 2017.

TARUFFO, Michele. Algunos comentarios sobre la valoración de la prueba.

Disponível em:< http://www.biblioteca.org.ar/libros/141670.pdf>. Acesso em 16 out. 2017. 